measurements of the yield of light under various conditions, and detailed spectroscopic studies such as those of the astrophysical type, may be expected to give further information in the not very distant future.

${ }^{1}$ Wolfhard. H. đ., and Parker, W. G., Proc. Phys. Soc.. A, 62, 722 (1949).

\section{ENERGY EXCHANGE BETWEEN THE OCEANS AND THE ATMOSPHERE}

$\mathrm{P}$ ROGRESS in oceanographical research and its applications to marine physical and biological problems is likely to be slow until more is known about the natural processes which regulate the water movements in the oceans and the distribution of physical properties. Interaction between the atmosphere and the oceans is the most important of these processes, and particular attention is being paid to it in marine physical laboratories ; the same information has useful applications to meteorology, and studies are being made of the vertical profiles of wind velocity, temperature and vapour pressure, close to the sea surface, and of the changes in heat and moisture content of air masses moving over the oceans. Recent progress formed the basis of a Geophysical Discussion held at the Royal Astronomical Society on October 28, at which Prof. P. A. Sheppard, of the Department of Meteorology, Imperial College of Science and Technology, and Mr. K. F. Bowden, of the Department of Oceanography, University of Liverpool, were the principal speakers.

The oceans gain most of their heat directly from the radiation of the sun, and it is estimated that they absorb nearly half the amount which reaches the outer limit of the atmosphere above them. The amounts received in different regions depend mainly on the latitude, time of year and the cloudiness of the sky. Since there is no appreciable change in the total heat content of the oceans, the gains must be balanced by losses, and it is known that heat is lost mainly by evaporation, by radiation to space, and to a lesser degree by conduction of heat from the water to the air. Regional heat balances are influenced to a considerable extent by the transfer of heat from one area to another by ocean currents.

The lower atmosphere gains most of its heat from the oceans; it is very transparent to direct radiation from the sun, and the difference between the amount of radiation reaching the upper limit of the atmosphere and that absorbed in the ocean is accounted for mainly by reflexion back to space from the atmosphere, clouds and water surface. The possible effect of absorption of short wave-length radiation in the very highest atmosphere is not known. Most of the heat is received from the condensation of water vapour, supplemented by direct conduction from the water. As in the oceans, there is no appreciable change in the total heat content from year to year, and the gains must be balanced by losses-chiefly by radiation to space. Numerical values have been given by various authors for the amounts of incoming and outgoing radiation in different latitudes and seasons, and also for the effect of reflexion from the sea, evaporation and conduction. They are all subject to revision ; but they are sufficiently accurate to lead to reasonable conclusions when applied to the oceans as a whole, and to areas in which the changes from month to month in the heat content of the water are known.

Such information is not often available, and the transfer of heat from the sea to the air in a particular region is usually estimated from information about the vertical gradients of temperature and vapour pressure near the surface, and about the turbulent processes by which they diffuse upwards into the atmosphere. Complete data are never available, but by using a formula developed by $H$. U. Sverdrup ${ }^{1}$ for evaporation at moderate and high wind-speeds, the routine observations, made by ships, of wind strength, sea temperature, and wet- and dry-bulb thermometer readings can be employed as a basis for the calculations. The amount of heat transferred by conduction can be calculated from the same figures, if it is assumed that the diffusion processes for temperature and water vapour are similar. W. C. Jacobs ${ }^{2}$ has prepared maps of the heat losses from all parts of the North Atlantic and North Pacific Oceans for which long-period climatic data are available. The main features of the maps are areas of maximum heat-transfer where the Gulf Stream and Kuro Siwo current carry warm water northwards off the east coasts of the United States and Japan, the amount being much greater in winter than in summer. Both areas are regions in which violent storms originate.

Mr. K. F. Bowden ${ }^{3}$ gave a brief description of his study (1948) of the heat transfer from the Irish Sea. Using assessments of incoming and outgoing radiation and measurements of the heat content of the water from month to month, he showed that the transfer of heat to the atmosphere is greatest in autumn and least in summer. He found some discrepancy between the heat transfer estimated by this method and that calculated from monthly figures for wind strength, sea and air temperatures, and relative humidity: In the discussion that followed, Prof. M. Neiburger (University of California) mentioned recent observations which suggest that there must be some revision of previous estimates of the effect of cloud. Mr. Bowden mentioned that there is some uncertainty about the formula for evaporation : some workers hold that the amount is practically independent of the state of the surface, while others suggest that it is four times as great for a rough as for a smooth surface. Other speakers remarked that discrepancies could result from the difficulty of making observations sufficiently close to the surface. Attention was directed to evidence that in calm and moderate weather there can be a thin film of water at the surface in which the temperature differs significantly from that measured by dipping a bucket. Mr. J. Francis argued that greater use should be made of laboratory models.

Several speakers emphasized the need for further study of the diffusion processes near the sea surface with simultaneous observations in air and water, the bebaviour of one being inexplicable without due regard to the other. Some disappointment was expressed that the state of knowledge and time available did not allow more to be said about the transfer of kinetic energy from the atmosphere to the sea; it was felt that there is a danger of underestimating the proportion of the heat content of the atmosphere which is turned into mechanicel energy, and of the fraction of this mechanical energy which is transferred to the oceans to contribute to the growth of waves, temporary wind drifts and permanent ocean currents. With reference to such transfer, Mr. H. Charnock showed that if data from every 
available source are plotted, the break between 'smooth' and 'rough' surfaces described by W. H. Munk $^{4}$ is not proved, though some of the other evidence, such as the abrupt change in the flight of seagulls at wind speeds of about 7 metres a second

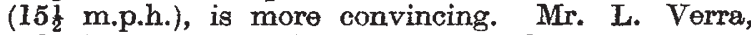
referring to preliminary results of measurements made to determine the tangential wind stress from the changes in slope of the surface of Lough Neagh, said that, although the observations show considerable scatter, they are in general agreement with the assumption that the stress is proportional to the square of the wind velocity for all wind strengths up to $20 \mathrm{knots}$. Using this assumption, the mean stress coefficient is 0.0013 , which is approximately the mean of all the other values that are available. If the observations are grouped according to air temperatures, there is evidence that the stress is greater when the air is unstable.

Prof. P. A. Sheppard gave some indication of how the calculation of heat transfer from the sea would be useful in meteorology and elimatology. Mr. J. Craddock, of the Forecasting Research Division, Meteorological Office, quoted a heat transport of $600 \mathrm{cal} . / \mathrm{cm} .2 /$ day from sea to air measured by observations at twenty-five points in the path of a particular air mass. This was understood to be in agreement with Jacobs's calculations for the North Atlantic Ocean in winter. Interaction with the oceans is only part of the meteorological problem; but the ocean surfaces are four times as extensive as the land, and some of the processes which require investigation may be simpler owing to the absence of topographical effects. The heat transfer is only part of the oceanographical problem, since the permanent ocean currents seem to derive most of their energy from the mechanical stress of the wind on the sea surface. Such a current may play an important part in determining the amount of energy which is available for transfer to the atmosphere in a particular region, and every change in the prevailing wind will lead to a change in the current which must again affect the atmosphere. The details of the interaction between the oceans and atmosphere have still to be worked out, and there is no doubt that their investigation offers great scope.

\section{G. E. R. Dracon}

${ }^{1}$ Sverdmup, H. U., J. Marine Research, 1, 3 (1937).

? Jacobs, W. C., J. Marine Research, 5, 37 (1942).

${ }^{3}$ Bowden, K. F., Mon. Not. Roy. Astro. Soc, Geophys. Supp., 5, 270 (1948).

‘ Munk, W. H., J. Marine Research, 6, 203 (1947).

\section{OPENING OF THE NATIONAL CHEMICAL LABORATORY OF INDIA}

$\mathrm{T}$

HE Council of Scientific and Industrial Research of India planned eleven national laboratories. The seventh of these, the National Chemical Laboratory, is nearing completion and was officially opened by the Prime Minister of India, Pandit Nehmu, on January 3. A description of the preliminary plans was given in Nature of February 15, 1947.

Begun in April 1947, the building, of Western design and magnificent proportions, makes an impressive picture set in a natural amphitheatre of hills about four miles from Poona. It is well equipped for scientific research in chemistry in both pure and applied fields, and when completely staffed will operate through nine departments; namely, organic chemistry, biochemistry, chemical engineering, plastics and high polymers, survey and information, inorganic chemistry, physical chemistry, adminis. tration and standardization of chemicals, development of bhilawan and cashew products. It will thus provide the possibility of effective co-operation between scientific research and industrial production

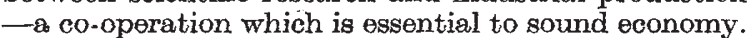

The important problem of collecting the right personnel for staffing is gradually being solved by the director, Prof. J. W. McBain, whose unceasing labour since his arrival in October 1949 is largely responsible for the advanced stage which the Laboratory has already reached. Several of the nine departments are already operating, and about seventy-six of the staff, which will ultimately number some one hundred and fifty scientific men, are appointed.

In his opening speech, Pandit Nehru stressed the importance of "personnel, which provides the essential spirit of an institution. It is more important than the buildings themselves, necessary and splendid though they are". He pointed out that "India has the people and the talent. The problem is to tap that talent. Money itself cannot be produced without people, and a country which is rich in talented people must therefore possess a potential source of wealth. People can make money, but money cannot make people. But it is not sufficient to make money alone, it is also necessary to concentrate on scientific advancement." He was surprised at the amazing ignorance of the importance of science to industry among industrial leaders. On the other hand, it might be said with justification that the Government had, during the past two years, done something in the matter of science and scientific research-it had at least laid the foundations of future work.

After the opening, Prof. McBain, addressing the large and distinguished audience, dedicated himself and the whole of the personnel to the service of the people of India and invited their co-operation, stressing its importance. He went on to speak of the ethical and spiritual qualities necessary for the pursuit of science. Science is in no way at variance with the highest spiritual and ethical aims, but must of necessity be integrated with them. Thus, devotion to truth, no matter how unwelcome or what personal self-sacrifice it involves, is, above all else, essential. Loyalty is also a requisite-loyalty both to the work undertaken and to humanity as a whole. Only those whose characters include such attributes are in a position to render any worthwhile service; but such true service, however small, is eternal in the mind of God.

The proceedings were presided over by His Excellency the Governor of Bombay. Others who took part were the Honourable Dr. Syama Prasad Mookerjee, Minister of Industry and Supply, and vice-president of the Council of Scientific and Industrial Research ; Sir Shanti Bhatnagar, director of scientific and industrial research; and four Nobel laureates, Sir Robert Robinson, Dr. A. H. Compton, Madame Joliot-Curie and Sir C. V. Raman.

After the opening, the Laboratory was inspected by Pandit Nehru, attended by the Director; and a large number of scientific workers, including many from overseas, toured the building and saw the numerous exhibits set up in the various laboratories already operating. About five thousand people attended the colourful ceremony. 